\title{
COLONIALIDAD Y DESCOLONIZACIÓN EN LA EDUCACIÓN LATINOAMERICANA: EL CASO DE LAS LICENCIATURAS INTERCULTURALES INDÍGENAS con el Pueblo Kaingang
}

COLONIALIDADE E DESCOLONIZAÇÃO NA EDUCAÇÃO LATINOAMERICANA: O CASO DAS LICENCIATURAS INTERCULTURAIS INDÍGENAS COM O Povo KaINGANG

COLONIALITY AND DECOLONIZATION IN LATIN-AMERICAN EDUCATION: THE CASE OF INDIGENOUS INTERCULTURAL Degrees with the Kaingang People

\begin{abstract}
Jorge Alejandro Santos
Pos-doctorando por la Universidade Comunitária da Regiāo de Chapecó. Bolsista da Coordenação de Aperfeiçoamento de Pessoal de Nível Superior (CAPES). Profesor de Pos-graduación en Filosofía de la Facultad de Filosofía y Letras y de Filosofía de la Ciencia en el Ciclo Básico Común en la Universidad de Buenos Aires, Argentina. jorgesantosuba@gmail.com

Leonel Piovezana

Doctor en Desenvolvimento Regional por la Universidade de Santa Cruz. Profesor del Programa de Postgrado en Educación y de la Licenciatura Intercultural Indígena da Universidade Comunitária da Regiăo de Chapecó, Brasil leonel@unochapeco.edu.br

\section{Luci Teresinha Marchiori dos Santos Bernardi}

Doctora en Educación Científica y Tecnológica por la Universidade Federal de Santa Catarina. Profesora del Programa de Postgrado en Educación y de la Licenciatura Intercultural Indígena da Universidade Comunitária da Regiāo de Chapecó, Brasil lucib@unochapeco.edu.br
\end{abstract}

Resumen: El artículo presenta una experiencia de implementación de educación intercultural y práctica decolonial en la formación de profesores indígenas del pueblo Kaingang en el marco de las Licenciaturas Interculturales Indígenas de la Universidade Comunitária da Região de Chapecó - Unochapecó. Partimos del diagnóstico de Adriana Puiggrós quien sostiene que el carácter colonial de la educación en Latinoamérica es un hecho histórico solapado y una situación que se debe revertir. Utilizamos las directrices pedagógicas de Paulo Freire releídas desde la perspectiva intercultural para poner en práctica una educación liberadora en la formación de profesores Kaingang y dentro de ese marco exponemos la experiencia de abordar problemáticas fundamentales para 
la población indígena que tiene que ver con las disputas territoriales y la visión de la sociedad no indígena sobre las comunidades originarias.

Palabras Clave: Decolonialidad. Kaingang. Interculturalidad. Liberación. Pedagogía.

Resumo: O artigo apresenta uma experiência de implementação da educação intercultural e prática descolonial na formação de professores indígenas do povo Kaingang no âmbito da Licenciatura Intercultural Indígena da Universidade Comunitária da Região de Chapecó - Unochapecó. Começamos com o diagnóstico de Adriana Puiggrós, que argumenta que o caráter colonial da educação na América Latina é um fato histórico sobreposto e uma situação que deve ser revertida. Utilizamos as orientaçôes pedagógicas de Paulo Freire em uma releitura da perspectiva intercultural para implementar uma educaçáo libertadora na formação de professores Kaingang e, nesse contexto, expomos a experiência de abordar problemas fundamentais para a população indígena que tem a ver com disputas territoriais e a visão da sociedade não-indígena sobre as comunidades originais.

Palavras-chave: Decolonialidade. Kaingang. Interculturalidade. Libertacão. Pedagogia.

Aвstract: The paper presents a practical experience of implementation of intercultural education and decolonial practice in the training of indigenous teachers of the Kaingang people in the context of the Indigenous Intercultural Bachelor of the Universidade Comunitária da Região de Chapecó - Unochapecó. We start with the diagnosis of Adriana Puiggrós who argues that the colonial character of education in Latin America is an overlapping historical fact and a situation that must be reversed. We use the pedagogical guidelines of Paulo Freire re-read from the intercultural perspective to implement a liberating education in the Kaingang teacher training and within that framework we expose the experience of addressing fundamental problems for the indigenous population like the territorial disputes and the vision of the non-indigenous society over the native americans communities.

KeYwords: Decoloniality. Kaingang. Interculturality. Liberation. Pedagogy.

\section{Introducción}

El presente artículo tiene como objetivo presentar una experiencia de educación indígena donde se desarrolla una práctica educativa dentro de la perspectiva intercultural y la práctica decolonial.

Coincidimos con los autores que escriben desde la perspectiva decolonial, como Adriana Puiggrós, que una de las características historicamente ocultada de la educación en Latinoamerica es el carácter colonial de la misma. Trabajamos dentro de ese marco teórico. Sin embargo entre la enunciación teórica de la filosofía intercultural y la perspectiva decolonial y la práctica educativa concreta hay un enorme vacío. Plasmar una práctica 
decolonial en el ejercicio de la educación cotidiana es un problema complejo que no suelen abordar los teóricos de la interculturalidad o la decolonialidad.

Como educadores nos interesa el diagnóstico general y el enfoque teórico original de la perspectica enunciada, pero nuestro principal interés es la práctica. Encontramos en una relectura intercultural de Paulo Freire (SANTOS, 20I7) un importante instrumento de mediación con la teoría. Freire fue un intelectual que se caracterizó por tener un claro foco en la aplicación concreta de sus desarrollos teóricos, su interés fundamental fue siempre la práctica educativa y su acción político-pedagógica.

A partir del diagnóstico citado y de una relectura de Freire desde una perspectiva intercultural, trabajamos durante el año 2017 dentro de las Licenciaturas Interculturales Indígenas dictadas por la Universidade Comunitária da Regiáo de Chapecó (Unochapecó), donde se forman profesores del pueblo Kaingang para que ocupen los cargos docentes en las escuelas de sus comunidades.

En síntesis el trabajo presenta una experiencia de educación intercultural y decolonial. Nuestra intención es mostrar que esta práctica, con sus tensiones y contradicciones, es posible y alienta a quienes comparten nuestra visión a poner en acción los grandes principios teóricos de la perspectiva en la que nos enrolamos. Creemos que es importante la discusión filosófica y la enunciación de principios, pero que sin un enfoque práctico que los haga realidad, la mera discusión teórica se convierte en una actividad agotadora y sumamente estéril.

A fin de alcanzar el objetivo propuesto en primer lugar plantearemos desde una perspectiva teórica el carácter colonial que, a nuestro entender tiene la educación el Latinoamérica, luego expondremos la metodología freireana como un instrumento para construir una educación diferente, y finalmente relataremos una de las experiencias prácticas realizadas con los estudiantes Kaingang en la Licenciaturas Interculturales Indígenas de la Unochapecó.

\section{Colonialidad en la educación latinoamericana}

¿Quién conoce en la práctica educativa? Freire sostiene que al hacernos esta pregunta se comienza a percibir que su contestación no es exclusi- 
va del ámbito de la pedagogía y que hay que matizarlo con el de la política. Pues se comienza a comprender que hay formas diferentes de contestarla y que estas conllevan una marca ideológica y una opción política. Por ejemplo, si uno contesta que quien sabe en la práctica educativa es el profesor, uno ha de preguntar enseguida: entonces ¡cuál es el papel de alumno? Quien diga que en la práctica educativa es el profesor quien sabe, dirá también, para ser coherente, que el papel del alumno es aprender, entendiendo el acto de aprender como el de recibir conocimiento del profesor. El profesor enseña y el alumno estudia y aprende. (FREIRE, I988)

En un contexto intercultural se tendrían que agregar, al menos, dos preguntas: Lo que se enseña y aprende ¿de qué contexto cultural procede? ¿En qué lengua se enseña y se aprende? Las respuestas a estas preguntas son importantes pues determinan el vehículo capaz de contener el conocimiento legítimo y, en consecuencia, el universo cultural al que éste pertenece. El que maneje la lengua será capaz de tener conocimiento, el que no, será incapaz.

En la educación que Freire llama 'bancaria' el que tiene el saber es el docente y quien tiene que aprender es el alumno, de tal forma que este último se trasforma en un receptor pasivo del saber. La educación liberadora viene a reconocer que el alumno tiene saberes previos y que el que enseña no sabe todo, de esta forma el proceso de aprendizaje se vuelve un acto de creación de conocimiento nuevo al que todos contribuyen enseñando y aprendiendo.

Si se educa desde una cultura hegemónica que impone el contenido de lo que enseña, así como el vehículo en que debe ser transmitido (la lengua) y el alumno a una cultura subalterna, silenciada y que, en ocasiones, ni siquiera maneja fluidamente la lengua del docente, estamos ante una situación de opresión mucho más profunda que la descripta por Freire con el adjetivo de 'bancaria'. Las relaciones de poder se hacen más asimétricas y para transformarlas no basta sólo un replanteo entre las relaciones de educador-educando, hay que redimensionar las relaciones entre las culturas que se ponen en contacto.

En el caso latinoamericano nos encontramos con una solapada y persistente situación colonial en el campo pedagógico que no ha sido revertida totalmente más allá de los esfuerzos y procesos en marcha. A continuación expondremos el origen de esa relación colonial. 


\subsection{El ritual del requerimiento como acto fundante de la pedagogía en Latinoamérica}

Adriana Puiggrós sostiene que el mayor pecado de la historiografía latinoamericana es haber ocultado la escena fundadora de la educación en Nuestra América: el Requerimiento redactado por el consejero de Fernando el Católico, Juan López de Palacios Rubio. Dicho documento era leído en español ante los pobladores (atónitos) de las tierras que 'descubrían'. Se trata de una explicación brevísima de la doctrina cristiana en tanto revelación de la "verdad" y del derecho a sujetar bajo su poder a las poblaciones indígenas; en caso de no aceptar la 'verdad' el texto amenaza con el exterminio de la población. Su extensión es considerable por lo que omitimos citarlo pero recomendamos su lectura. (SANTOS, 2017, p.II5-II6)

La escena del Requerimiento es de enorme significación y condensación simbólica, pues implica la fundación de una relación pedagógica y la creación de una forma particular de dominación caracterizada por la falta de registro de los discursos indígenas en los de sus conquistadores. Del más importante debate pedagógico de la época colonial, el de los 'justos títulos', no surge la decisión de ningún intercambio cultural, de incorporación alguna de elementos culturales indígenas a lo europeo. La resistencia de los espańoles a la penetración cultural indígena fue de hierro. Se impuso su palabra, su nombre, y su dios congelado. Identificaron a los indígenas por su ignorancia de la lengua y la religión dominadora y no por el conocimiento de la propia. Los seńalaron como no educados y los sospecharon incapaces de educación. (PUIGGRÓS, 1996)

El Requerimiento revela que la conquista tiene, además de una justificación religiosa-teológica, una justificación pedagógica. El imperio espańol, como cualquier otro imperio (incluido el Portugués), no justificaba sus actos diciendo que su poder militar les daba derecho a ocupar el territorio que tuvieran a su disposición. El fin de la conquista fue: civilizar, evangelizar, llevar la verdadera religión a los que vivían en la ignorancia, el error, la idolatría y el pecado.

El saber justifica al poder y el poder al saber. Las características de la relación pedagógica que se crea en la conquista son: 
- Negación de cualquier intercambio cultural.

- Cercenamiento de cualquier posibilidad de incorporar elementos de la cultura indígena a lo europeo.

- Imposición de la lengua y la religión.

- Identificación de los indígenas por su ignorancia (desconocimiento de la lengua, religión y ciencia europea) y no por su conocimiento (el de su propia cultura, lengua, religión y ciencia).

\subsection{La herencia colonial}

El ritual del Requerimiento como acto fundante de la pedagogía en Latinoamérica es una imagen muy potente. Y si bien la negativa de la Corona espańola de incorporar elementos de la cultura indígena fue la regla, lo cierto es que la cultura indígena encontró lugares y estrategias de resistencia, penetración y subsistencia. La conquista no exterminó totalmente las culturas originarias de América ni mucho menos, si así hubiera sido no podríamos hablar del resurgimiento de 1992.

Así como la política de exterminio de la conquista no pudo terminar con las culturas originarias, la etapa de las luchas por la independencia que ponen fin a la relación política colonial con España no da fin, ni mucho menos, al carácter colonial de las sociedades en los nuevos estados independientes. Perdura lo que, en términos establecidos por Aníbal Quijano (1995) y incorporados por Souza Santos (2006), se nombra como la colonialidad del poder o, en palabras más sencillas: en los nuevos Estados perduran las relaciones coloniales del poder y del saber, perdura la admiración por lo moderno y europeo y el desprecio por lo indígena identificado como primitivo. En el campo de la pedagogía perdura la relación pedagógica colonizadora fundada por el Requerimiento.

El proyecto de la independencia americana busca consolidar Estados independientes y modernos, las elites que lo llevan adelante tienen entre sus ambiciones crear un sistema educativo acorde a este proyecto. En Argentina y Chile este impulso es clarísimo: el padre de los sistemas educativos es la misma persona, Domingo Faustino Sarmiento. El impulso modernizador y europeizante de las elites de la independencia es mucho mayor que el de la decaída administración colonial: "En nuestros 
tiempos de civilización homogénea y universal, americana, europea, de líneas de vapores por caminos y de cables submarinos por estafeta, el patriotismo como recuerdo, es simplemente una enfermedad que se llama nostalgia." (SARMIENTO, I970a, p. 90)

Según Piovezana (2007), en Brasil la política respecto a la población indígena es similar, sin bien la dinámica de la independencia brasilera y su configuración cómo república tiene diferencias significativas respecto de la independencia de las colonias españolas. En el período colonial y hasta finales del siglo in la ocupación del territorio indígena se iniciaba con una campaña militar y continuaba con la reducción de la población indígenas a aldeas para catequizarlos. Es decir, en este período la educación indígena estaba ligada a una perspectiva religiosa dirigida por la Iglesia Católica que actuaba como sustituto del Estado y tenía como finalidad la conversión religiosa con la consecuente desaparición de la cultura indígena, sus instituciones y sus valores tradicionales. Este esquema se mantiene con pocas variantes hasta finales del siglo XIX.

Las lecturas y los ejemplos a seguir para la generación de la independencia provenían de la modernidad francesa e inglesa (esta última expresada en el ejemplo de la "otra América"). Por lo que la relación de subordinación colonial con la cultura europea no es desmontada por las revoluciones de la independencia, al contrario, en muchos aspectos es profundizada. Cuanto mayor es el impulso modernizador de las elites, mayor es el sojuzgamiento de las culturas tradicionales: “¿Qué le queda a esta América para seguir los destinos prósperos y libres de la otra? Nivelarse; y ya lo hace con las otras razas europeas, corrigiendo la sangre indígena con las ideas modernas, acabando con la Edad Media." (SARMIENTO, I97ob, p. 94)

El proyecto de la modernidad americana tiene entre sus objetivos terminar con la cultura indígena corrigiéndola con las "ideas modernas", incluso recurriendo al remplazo de la población autóctona por inmigrantes europeos. Es muy curiosa la identificación sarmientina de la "sangre indígena" con la "Edad Media". Esta identificación proviene de una valoración ideológica que llama a todo lo que está fuera de la cultura moderna - 'Edad Media' ¿Cuál es la relación de las culturas originarias de América con la Edad Media europea? Ninguna, la asimila- 
ción es un absurdo en términos históricos, geográficos y culturales, sin embargo es un discurso totalmente verosímil para varias generaciones de latinoamericanos.

Enrique Dussel (2000) sostiene que hay una primera modernidad europea encabezada por Espańa y Portugal, potencias del viejo continente que realizan el descubrimiento y la conquista de América. Esta primera modernidad hace posible el surgimiento de Europa como el bloque hegemónico (centro del sistema-mundo en palabras de Dussel) a nivel global. Según el autor, sin los territorios y los recursos provenientes de América la segunda modernidad europea no hubiera sido posible. Las potencias que consolidan su poder en siglo XVIII, Francia e Inglaterra, y fundan lo que entendemos comúnmente como 'cultura moderna' niegan estratégicamente la primera modernidad espańola y portuguesa asimilándola con el oscurantismo medieval. A la luz de esta tesis, es comprensible que las elites modernizadoras americanas asimilen (ideológicamente) en un solo bloque culturas originarias, herencia española-portuguesa y cultura criolla o cabocla con Edad Media o oscurantismo medieval. En consecuencia los sistemas educativos modernos en nuestros países no sólo se establecen sobre el olvido y el silencio del acto fundante de la pedagogía Latinoamericana, sino que perpetuán y profundizan el proyecto esbozado por éste.

La pedagogía crítica en nuestro continente no puede seguir habitando en este silencio. A excepción de Mariátegui, lo mejor de la pedagogía latinoamericana se desarrolla sobre este olvido, el propio Freire no lo tematiza. Y si bien las sociedades latinoamericanas luego de la conquista, la independencia y los procesos de modernización adquirieron una complejidad tal que es imposible reducir a las relaciones pedagógicas a términos de españoles/indígenas, o europeos/americanos, persiste la situación colonial en los vínculos pedagógicos. Se expresa por ejemplo en la invisibilización de los pueblos originarios que conservan su lengua y tradiciones dentro de las historias y culturas nacionales.

Incluso las categorías más radicales de la etapa de la Pedagogía del Oprimido no son adecuadas para hacer visible y deconstruir esta herencia colonial. Sin embargo son un instrumento útil si las reformulamos interculturalmente. 


\section{Relectura intercultural de los principios freireanos}

Consideramos a la pedagogía de Paulo Freire la más adecuada para enseñar en el contexto intercultural que caracteriza a Latinoamérica. Sin embargo el pedagogo brasilero no aborda específicamente la problemática de la educación indígena por lo que es necesario adaptarla o releerla desde una perspectiva intercultural. Presentaremos esta relectura de manera breve, para un estudio mas detallado remitimos a otra publicación (SANTOS, 20I7) donde se desarrolla detalladamente la temática.

Para esto seleccionamos los nodos conceptuales que atraviesan y dan coherencia al pensamiento freireano y lo reinterpretamos desde la perspectiva filosófica intercultural para adaptarlos al contexto descripto. Los núcleos conceptuales seleccionados son los siguientes: la afirmación del carácter político de la práctica educativa, dialogicidad y partir del contexto del educando. La importancia de estos nodos, además de su carácter de principios pedagógicos del proceso educativo, reside en la posibilidad de articularlos en un método de alfabetización de adultos y post alfabetización con aplicaciones y resultados asombrosos. Este método, así como los principios que lo inspiran, ha sido retomado como modelo por infinidad de grupos de educadores populares que desarrollan su actividad político-pedagógica en los sectores más olvidados de Latinoamérica y todo el "Tercer Mundo".

\subsection{Politicidad de la educación en un contexto intercultural}

Tenemos por un lado las relaciones de poder propias de la actividad educativa, donde se distribuyen roles de acuerdo a quien tiene el conocimiento y quien no, por lo que no es lo mismo sostener que el profesor sabe y el alumno ignora, que suponer que ambos saben en parte y también algo ignoran. No es lo mimo educar dialogicamente para una sociedad democrática que hacerlo para la cultura del silencio. Pero además en un contexto intercultural tenemos la presencia de, al menos, dos culturas que entran en contacto por lo que el carácter político de la educación se hace más evidente. 
Las relaciones entre culturas siempre implican relaciones de poder más o menos asimétricas, más o menos intensas. Existen palabras para referirse a esta variedad de relaciones: integración, asimilación, autonomía, autodeterminación, conquista, colonización etc. Es decir existe un carácter político ineludible en lo intercultural y esta politicidad se yuxtapone, en el contexto concreto de la práctica educativa intercultural, con la politicidad intrínseca de la educación.

Todorov (2008) ha realizado un trabajo fundamental de sistematización que nos ayuda a entender y poner en evidencia cómo se construyen y yuxtaponen las relaciones de poder y de conocimiento en relación al otro cultural. Señala con razón que "generalmente el vencido es el que aprende el idioma del vencedor. No es casual que los primeros interpretes sean indios: los que Colón se lleva a Espańa, los que vienen de las islas ya ocupadas por los españoles ('Julian' y 'Melchor'), la Maliche, regalada a los espańoles como esclava." (TODOROV, 2008, p. 230) Asimismo del lado español los que aprenden la lengua están en posición de inferioridad: "Aguilar o Guerrero obligados a vivir entre los Mayas, o más tarde Cabeza de Vaca. No imaginamos que Colón o Cortés aprendan la lengua de aquellos que someten, e incluso Las Casas nunca llega a dominar una lengua indígena." (ibib.)

La resistencia a incorporar la cultura indígena a los sistemas educativos coloniales y luego nacionales ha sido de hierro tanto en la América hispana como en la lusa. Apenas hace algunas décadas se reconoce el derecho de las comunidades a ser educadas no solo el la lengua, valores, saberes y creencias de la sociedad envolvente, sino además en la suya propia. Ese es el desafío que enfrentamos al que tenemos que sumarle la dificultad de revertir 500 años de aculturación y etnocidio.

\subsection{Dialogicidad en un contexto intercultural}

En el contexto en el que trabajamos la necesidad de diálogo es acuciante, es necesaria la comunicación y la escucha entre los participantes del proceso educativo y, a través de ellos, la comunicación y escucha entre culturas, eso da el carácter de inter(entre)cultural a la educación. La necesidad de escucha y de aprendizaje intercultural es mayor entre los profesores que 
estamos formados en la cultura nacional envolvente, que de parte de los alumnos ya que por su experiencia cotidiana saben concretamente de que se trata el vivir entre (inter) dos culturas.

\subsection{Partir del contexto del educando}

Esta tercer premisa implica un desafío para nuestra experiencia pues no solo supone ligar el conocimiento matemático al la experiencia vivencial y concreta de los alumnos sino vincularlo con su universo cultural. Fue y es un gran desafío pues, como profesores, tuvimos que alfabetizarnos en la cultura Kaingang y aún esforzándonos siempre tendremos un conocimiento más limitado que los propios alumnos.

\section{La experiencia de las Licenciaturas Interculturales Indígenas da Unochapecó}

La Licenciatura Intercultural Indígena comenzó a dictarse na Unochapecó a partir de la Resolución 053/CONSUN/2009. Su ejecución tuvo lugar en la segunda mitad de ese año con un régimen particular: se desarrollan de manera intensiva dentro de las Tierras Indígenas (TI) Kaingang y en forma presencial a los viernes y sábado. La carga de trabajo es de 4215 horas, con una duración de Io semestres y con sesenta lugares para la formación.

El curso da el título de Licenciado Intercultural Indígena en uma das seguintes áreas: Pedagogía, Matemáticas y Ciencias Naturales; Humanidades y Ciencias Sociales; Idiomas, Arte y Literatura (UNOCHAPECÓ, 20I2, p. 25-27). Tiene por objetivo la formación y la habilitación de profesores indígenas para el ejercicio docente en educación infantil, enseñanza fundamental y en disciplinas específicas de la enseñanza media, conforme el área en las que hicieran opción. Los objetivos específicos de los cursos expresan una dinámica de formación de la calidad cresciente, anclada en el contexto cultural, social, económico y geográfico, y en la permanente relación teoría-práctica, en tres niveles de competencias: 
a) Compreensão do processo de educação escolar, dos seus limites e possibilidades, como uma nova prática social e cultural que se expressa em novas relaçóes econômicas, políticas, administrativas, psicossociais, lingüísticas e pedagógicas;

b) Domínio de conhecimentos autóctones e das ciências que integram o currículo dos Cursos de Licenciatura e de sua adequada utilização na realidade sociocultural específica em que atua como professor.

c) Capacidade de organização e dinamização do currículo escolar e de implementação de estratégias didático-pedagógicas consonantes com as demais práticas culturais utilizadas por uma sociedade ou por uma determinada comunidade. (UNOCHAPECÓ, 2009, p. 52)

En la primer llamada se inscribieron 96 postulantes de los que fueron seleccionados 6o. Fue una tarea ardua para los profesores que tuvieron que "aprender" el nuevo contexto y hacer un esfuerzo para la inserción contextual de los contenidos de la licenciatura también para los alumnos pues el nivel de exigencia es alto. El dictado en las propias tierras indígenas de los cursos resolvieron uno de los principales problemas de la formación de profesores indígenas: la alta evasión de los estudiantes. Los resultados fueron muy buenos: en el 20I4, 34 alumnos recibieron el grado de licenciatura y otros 24 completaron el curso pero dejaron materias pendientes que están volviendo a cursar. Es decir, el porcentaje de evasión se invirtió: el 90\% mantuvo la regularidad y un 10\% abandonó el curso. Esto demuestra lo efectivo de las políticas pública aplicadas. Los profesores formados están trabajando en los diferentes niveles de la educación indígena.

Una nueva camada de profesores se está formando hoy y si bien el dictado del curso presenta dificultades, el principal obstáculo se ha vencido: la evasión de estudiantes se redujo de manera sustancial. En este contexto expondremos una experiencia que puede parecer poco relevante en un principio pero que es sustancial si se analizan detalladamente el planteo inicial, las reflexiones obtenidas, los resultados y las nuevas perspectivas que se abren a partir de ella.

El trabajo a exponer se realizó con el grupo que se forma en el área de Humanidades y Ciencias Sociales. Siguiendo la metodología freireana 
de politicidad, dialogicidad y contexto del educando, al abordar el área de geografía y territorialidad se puso especial énfasis en las disputas territoriales de los pueblos indígenas de Brasil, el estatus territorial y geográfico de las Tierras Indígenas, y más específicamente la situación de Tierras Indígenas Kaingang en el Oeste de Santa Catarina. Esto a fin de que los conceptos geográficos se referencien en el contexto de los estudiantes, la problemática de sus comunidades y no sean meros conceptos "abstractos" o "bancarios", en terminología freireana. Trabajamos entre otros textos Perspectivas Kaingang sobre o direito territorial e ambiental no Sul do Brasil (FERNANDEZ; PIOVENZANA, 2015). Lo interesante de la experiencia no es necesariamente la literalidad de la temática y el abordaje de lo textos sino lo que estos textos y temáticas producen y generan en el aula en un contexto de sincero diálogo pedagógico e intercultural.

Las reflexiones que disparó el texto van mucho más allá del contenido del mismo. En su introducción, antes de describir la situación de cada TI Kaingang del oeste catarinense, se refiere a la visión de sentido común que tiene la sociedad envolvente sobre el indígena:

Ser índio no sul é, na versão hardcore do senso comum, ser vagabundo; é contar com a tutela generosa da FUNAI; é poder dispor de terras e os recursos naturais à vontade. Em sua versão light, o senso comum, vê os índios como excluídos genéricos; credores de uma dívida histórica que, como outras tantas, jamais será paga [...] Se, em muitos casos, o senso comum é reduto seguro da razão sociológica, neste caso, em particular, é uma armadilha. (op.cit., p. II5)

En la clase, con dinámica dialógica freireana, se comentó esa parte introductoria del texto, luego de un momento de silencio y cierto asombro sobre el tema abordado, la armadilha planteada fue reelaborada por una alumna: "es cierto profe, escuchamos mucho eso de que los indios somos vagabundos, que no nos gusta trabajar, que dejamos venir el mato y no trabajamos la tierra, es muy común algunos lo dicen fuerte incluso en el transporte público para que nosotros escuchemos [...]”; enseguida otro alumno completó: "Pero si algún indígena trabaja la tierra, hace un buen negocio, progresa económicamente, compra un carro, o buena ropa en- 
tonces dicen que ya no somos indígenas y que no merecemos los derechos indígenas a nuestro territorio.'

Como profesores percibimos que se trataba de un tema sensible y del que no era fácil hablar en un contexto intercultural con profesores no indígenas. Reencaminamos la temática de la clase hacia ese tópico que exponía una suerte de paradoja o trampa verbal con la que los estudiantes estaban muy familiarizados. La sociedad envolvente y su discurso de sentido común hacia la persona indígena plantea una suerte de trampa dialéctica, una falsa opción entre mantener una forma de vida tradicional (y por lo tanto ser vagabundo y no merecer la tierra) o no mantener la vida tradicional, trabajar e incorporarse al sistema y modo de producción envolvente (y por lo tanto dejar de ser indígena y perder el derecho al territorio).

El diálogo fue encaminado hacia el por qué de ese discurso francamente contradictorio y perturbador hacia la sociedad indígena, luego de algunos intercambios, silencios y de insistir en el por qué una de las alumnas conjeturó timidamente: "por la tierra?". Discutimos la conjetura y volvimos necesariamente al tema de la clase: territorios indígenas, conflictos, historia de las TI kaingangs y situación actual. Y además abordamos la dialéctica colonial sobre estas disputas y finalizamos con la pregunta de cómo defenderse de esa argumentación prejuiciosa, peligrosa y que colocaba a la población indígena en una situación de debilidad. La respuesta sobre cómo lidiar con esta "armadilha" es de fundamental importancia pues se están formando profesores para trabajar en las comunidades que necesitan de herramientas para desarmar estas trampas y fortalecer la identidad y autoestima de los estudiantes.

En el diálogo conjeturamos una posible respuesta: en primer lugar no creer el argumento, ser conscientes de que la intención es desprestigiar los reclamos indígenas, recordar que los indígenas son ciudadanos brasileros con todos los derechos nacionales más algunos derechos diferenciales por su condición de indígenas reconocidos incluso en la constitución federal, fortalecer la identidad y la autoestima de las nuevas generaciones. Sin embargo quedó la sensación de una respuesta incompleta aún que, como profesores e investigadores, percibimos que era un tema importante a investigar. 


\section{Paradojas y dobles vínculos en auxilio de la perspectiva decolonial}

En este punto es importante señalar que este artículo surge de un trabajo conjunto que en sí mismo es una práctica intercultural pues parte de los aportes de profesores de la Unochapecó que trabajan dentro de las aldeas en el programa, estudiantes de las Licenciaturas Interculturales Indígenas y la colaboración de investigadores de la temática pertenecientes a la Universidad de Buenos Aires (UBA), Argentina. La colaboración binacional se da principalmente a través de una estancia posdoctoral en el Programa de Postgraduación en Educación (PPGE) de la Unochapecó de un investigador especializado en el área de educación intercultural indígena perteneciente al proyecto UBACYT: "La noción de ciudadanía Sudamericana desde una perspectiva ético-política intercultural. Estudio crítico a partir de los proyectos del MERCOSUR, la UNASUR, la CAN y la CSN" radicado en la Sección de Ética, Antropología y Filosofía Intercultural del Instituto de Filosofía de la Facultad de Filosofía y Letras, UBA. La estancia posdoctoral es financiada por una beca de la Coordenação de Aperfeiçoamento de Pessoal de Nível Superior (CAPES).

Esta colaboración nos permite analizar lo que sucede en el aula desde diferentes niveles y perspectivas. En especial nos dimos cuenta de que la estructura argumental paradójica o de trampa verbal enunciada es similar a la utilizada en conflictos territoriales con poblaciones indígenas y campesinas en otros contextos nacionales. Durante el ańo 2017 tomaron estado público conflictos territoriales con comunidades Mapuches de sur de Argentina y uno de los argumentos sostenido incluso desde medios masivos de comunicación fue el del "indio trucho" o "indio falso":

La mayor potencia de ese relato reside, justamente, en que nos ofrece un sujeto indígena igual al que relató la historia canónica de la Argentina. El indio de los manuales escolares es en blanco y negro, es harapiento, vive en una choza, mal alimentado $y$, por todo esto, no puede querer ser quien es (NOVARO, 2003). No hay en ese sujeto felicidad ni lucha posible. Su contrapartida es "el indio trucho" de Lanata. Que representa valores e ideas que no están en ese imaginario. (ENRIZ, 20I8, p. I) 
Vemos aquí un argumento que si bien varía en algunas consideraciones y valoraciones es equivalente es su estructura lógica o argumentativa, por una parte el "indio verdadero" de los manuales escolares pobre, harapiento, que no puede querer ser quien es y por lo tanto no puede ser sujeto de felicidad y lucha, y por otro lado el "indio falso" que se quiere aprovechar del Estado reclamando derechos que no le pertenecen haciéndose pasar por indio. Es decir, si se trata del "indio verdadero" no puede querer ser quien es y para salir de esa condición paupérrima tiene que adoptar la forma de vida de la sociedad envolvente, pero si eso sucede deja de ser indígena (es un "indio trucho") y ya no tiene derechos a reclamo: es decir nunca tiene derechos en tanto indígena haga lo que haga.

Pero más llamativo aún es que la misma estructura argumentativa fue usada en un contexto totalmente diferente al de poblaciones indígenas en Latinoamérica. Wolin (2003), en su libro Los hijos de Heidegger, donde habla de cómo lidian con la herencia del filósofo sus discípulos judíos más notables (Arent, Marcuse, Lowït y Jonas), sostiene al referirse a la situación de la población alemana de origen judío:

Irónicamente, mientras que anteriormente se había criticado a los judíos por seguir demasiado apegado a sus ritos medievales y sus costumbres de gueto, durante el Segundo Imperio se los criticó por haber abandonado sus antecedentes tradicionales judíos y tratar de «hacerse pasar por alemanes», en lo esencial por ser un pueblo sin identidad. (WOLIN, 2003, p. 77)

A la luz de la evidencia recolectada la estructura argumentativa responde a la finalidad de socavar, desgastar, minar la identidad y autoestima de una población o grupo étnico determinado a fin de no reconocer sus derechos. Es evidente que si los judíos alemanes no dejaban sus ritos tradicionales no serían reconocidos sus derechos cómo ciudadanos alemanes, y si los dejaban tampoco los reconocerían como tales, nuevamente la misma estructura paradójica y el mismo callejón sin salida.

Watzlawick (2002, p. 96), en sus estudios sobre la comunicación humana y estrategias de manipulación, llama a este argumento falaz ilusión de alternativas: 
[...] se da aquí una presión para elegir entre dos alternativas, pero se trata de una elección que o bien es ilusoria porque ninguna de las dos es adecuada o, por cualesquiera otras razones, es imposible en la práctica. La persona prisionera de este caso, por tanto, dammned if he does and damns if he does not (condenada si lo hace y condenada si no lo hace), como dice una acertada frase inglesa.

He aquí algunos ejemplos:

I. Heads I win, tails you lose, dice otra expresión inglesa, muy difundida, que alude a costumbres de echar al aire una moneda para decidir una cuestión y que podría traducirse algo así como: «Si sale cara gano yo, si sale cruz pierdes tú.» $\mathrm{Al}$ parecer, se deja la decisión en manos de imparcial azar. Pero basta un mínimo de atención para advertir que las dos alternativas son ilusorias, porque en la base de este acuerdo el otro pierde en los dos casos. No tiene ninguna posibilidad de ganar.

Esta estructura paradójica es estudiada por Watzlawick a nivel de comunicación familiar pues su foco de interés son los efectos psicológicos a nivel individual. Sostiene que este tipo de mensaje, llamado doble vinculo (double bind), es típico en la interacción de las familias de esquizofrénicos. Se trata de un discurso enloquecedor, los nińos expuestos a estos tipos de mensajes tienen enormes dificultades para consolidar su identidad personal y corren serios riesgos de padecer esquizofrenia.

Los efectos de este tipo de comunicación a nivel familiar e individual no pueden trasladarse sin más al nivel social o a la relación entre la sociedad envolvente y la población indígena. Sin embargo la hipótesis de que este discurso enloquecedor tiene como finalidad manipular, debilitar la identidad de la población, la conciencia sobre sus derechos individuales y colectivos y su capacidad para defenderlos y reclamarlos, es perfectamente verosímil. Lo cierto es que en el caso particular de la población Kaigang, el argumento sostiene que si se sigue con la forma de vida tradicional los indígenas son unos vagos por lo que no merecen a tierra, y en caso de que la trabajen al modo de un agricultor no indígena, usen maquinarias, tengan auto o celular, entonces dejan de ser indígenas por lo que pierden sus derechos a la tierra. Conclusión: no merecen la tierra en cualquier alternativa, 
se trata de alternativas ilusorias típicas de un discurso enloquecedor. Estos discursos, además de falaces, ni son éticos ni contribuyen al bienestar o salud mental de la población, más bien todo lo contrario son altamente perturbadores.

¿Cómo defenderse de este tipo de argumentación? Watzlawick sostiene que hay que colocarse en un nivel metalinguístico a fin de denunciar la paradoja y la falsa alternativa. Y justamente ese es uno de los objetivos de este artículo.

La alternativa real es establecer qué condiciones concretas, posibles y legales deben cumplirse para que se reconozca el derecho a la tierra de una población indígena que reclama un territorio, si se cumplen se reconoce, si no se cumplen no. La falsa alternativa es una estrategia de comunicación que tiene como finalidad que nunca se reconozca ese derecho bajo ninguna condición. Este estudio busca contribuir a que se consolide la identidad de los Kaingang como pueblo y la conciencia de sus derechos como indígenas y como ciudadanos brasileros y latinoamericanos. Es necesario poner en evidencia los mensajes perturbadores dirigidos a la población indígena en este caso en particular y en otros similares en nuestro continente. La descolonización y consecuente aceptación del carácter intercultural de las sociedades latinoamericanas requiere de muchos pequeńos esfuerzos, cotidianos, constantes y concretos.

\section{Conclusiones}

El objetivo del artículo ha sido cumplido, enunciamos el marco teórico desde una perspectiva intercultural y decolonial, luego el marco pedagógico de la pedagogía freireana releída inteculturalmente, y finalmente presentamos lo que consideramos la parte más importante y original de este artículo: una experiencia de educación intercultural y una práctica pedagógica decolonial.

En la experiencia relatamos el desarrollo de una temática en el área de geografía dentro de las Licenciaturas Interculturales Indígenas de la Unochapecó. Contextualizamos los tópicos geográficos en relación a la situación territorial de las TI Kaingang. En ese marco una de las estudiantes enunció un argumento en torno a la población indígena y sus reclamos 
territoriales de claro corte colonial: identifica a los indígenas como vagos y perezosos por lo que no tenían derecho a la tierra ya que no la trabajan, pero en caso de que un indígena adoptara el modo de vida y producción de la sociedad envolvente entonces se argumentaba que ya no es indígena, que no es un "indio verdadero" por lo que tampoco tiene derecho a la tierra. Es decir, un indígena nunca tiene derecho a la tierra.

Profundizamos el análisis de este argumento a fin de desmontarlo y dejar en evidencia su carácter falaz, su intención de socavar la identidad, lo reclamos y derechos de las poblaciones indígenas de la región, e incluso conjeturamos posibles efectos perturbadores en el bienestar psíquico de la población.

Analizamos la estructura retórica del argumento, encontramos que se correspondía con argumentos similares utilizados en contextos muy diferentes y postulamos una estrategia para desmontarlo: denunciar la falsedad de alternativas, instalarse en un nivel metalingüístico para poner en evidencia que se trata de opciones ilusorias que tienen como único objetivo negar el carácter de sujetos de derechos específicos que tienen las poblaciones indígenas.

Estamos conformes con el resultado a nivel teórico y a nivel práctico pues seguramente este artículo formará parte del curriculum y de las discusiones de los nuevos cursos de las Licenciaturas Interculturales Indígenas en Unochapecó.

\section{Referencias}

DUSSEL, Enrique. Europa, Modernidad y Eurocentrismo. In: LANDER, Edgardo (Org). La colonialidad del saber: eurocentrismo y ciencias sociales. Perspectivas latinoamericanas. Buenos Aires: CLACSO, 2000.

ENRIZ, Noelia. Los medios contra los indígenas: el verso del indio trucho. Revista Anfibia, Universidad Nacional de San Martín. Disponible en: http://www. revistaanfibia.com/ensayo/verso-del-indio-trucho-2/. Acceso: 8 enero 2018.

FERNANDEZ CID, Ricardo; PIOVENZANA Leonel. Perspectivas Kaingang sobre o direito territorial e ambiental no sul do Brasil. Ambiente \& Sociedade, Sáo Paulo, v. XVIII, n. 2, p. II5-I32, abr./jun. 2015. 
FREIRE, Paulo. La educación para una transformación radical de la sociedad. In: MAZÓ, Pere Soler (Org.). Una educación para el desarrollo: la animación sociocultural. Madrid: Fundación Banco Exterior, 1988. p. I3-24.

PIOVEZANA, L. A Educação no indígena Kaingang. In: Os Kaingang no oeste catarinense: tradição e atualidade. Chapecó: Argos, 2007.

PUIGGRÓS, Adriana. Presencias y ausencia en la historiografía pedagógica latinoamericana. In CUCUZZA, H. (Comp.). Historia de la educación en debate. Buenos Aires: Ed. Miño y Dávila, I996. p. 9I-II9.

SANTOS, Jorge A. Filosofía Intercultural y Pedagogía. Buenos Aires: Teseo, 2017. SARMIENTO, Domingo F. La nostalgia de América. In: RIPOL Carlos (Ed.). Conciencia Intelectual de América. Antología del ensayo Hispanoamericano (1936-1959). New York: I970a, p.90.

SARMIENTO, Domingo F. Conflicto y armonía entre razas en América. In: RIPOL Carlos (Ed.). Conciencia Intelectual de América. Antología del ensayo Hispanoamericano (1936-1959). New York: I970b, p.94.

SOUSA SANTOS, Boaventura de. Conocer desde el Sur: para una cultura política emancipatoria. Santiago de Chile: Editorial Universidad Bolivariana, 2006.

TODOROV, Tzvetan. La conquista de América: el problema del otro. Buenos Aires: Siglo XXI, 2008.

UNOCHAPECÓ. Projeto de Criação de Curso de Licenciatura Especifica para a Formação de Professores Indígenas Kaingang. Chapecó SC, Brasil, 2009.

UNOCHAPECÓ. Curso de Licenciatura Intercultural Indigena - Pedagogia. Processo de reconhecimento do curso de graduação em Licenciatura Intercultural Indígena em Humanidades e Ciências Sociais. Chapecó SC, Brasil, 2012.

WATZLAWICK, Paul. El lenguaje del cambio. Barcelona: Herder, 2002.

WOLIN, Richard. Los hijos de Heidegger. Madrid: Ed. Cátedra, 2003.

Recebido em 25 jan. 2018 / Aprovado em 20 mar. 2018

Para referenciar este texto

SANTOS, J. A.; PIOVEZANA, L.; BERNARDI, L. T. M. S. Colonialidad y descolonización en la educación latinoamericana: el caso de las licenciaturas interculturales indígenas con el pueblo kaigang. EccoS - Revista Científica, São Paulo, n. 45, p. 59-78. jan./abr. 2018. Disponível em: <https://doi.org/Io.5585/EccoS.n45.828I >. 